\title{
Husbands' involvement in antenatal care and its association with women's utilization of skilled birth attendants in Sidama zone, Ethiopia: a prospective cohort study
}

Wondwosen Teklesilasie ${ }^{1,2^{*}}$ and Wakgari Deressa ${ }^{3}$

\begin{abstract}
Background: There is limited evidence about husbands' roles on women's utilization of skilled maternity care in Ethiopia, a country with low utilization coverage of skilled birth attendants and high maternal mortality. This study examined the association between husbands' involvement in antenatal care and women's use of skilled birth attendants in Sidama zone, Southern Ethiopia.

Methods: Using a cohort study design, we followed a random sample of 709 antenatal women until delivery from June 01 to November 30, 2015. Main exposure variable was husband's involvement in at least one antenatal care visit, and outcome variable was women's use of skilled attendants during birth. Data were analysed using SPSS software-version20. We computed univariate and bivariate analyses to describe characteristics of the study subjects. A chi-square test with $p$-value $<0.05$ level of significance and logistic regression analyses with odds ratio and $95 \%$ confidence interval were computed to test homogeneity of the two groups' baseline characteristics and examine the association between husbands' involvement in antenatal care and women's use of skilled attendants during birth. Model assessment of the regression equation was checked using a likelihood ratio test, score test, and Hosmer-Lemeshow goodness-of-fit test.
\end{abstract}

Results: Women who reported at least one antenatal care visit in which their husbands accompanied them were 6. 27 times (95\% Confidence interval: 4.2, 9.3) more likely to use skilled birth attendants compared to women attended antenatal care alone.

Conclusion: There was a strong statistically significant association between husbands' involvement during antenatal care and women's use of skilled attendants during birth. This implies that woman's utilization of skilled attendants during birth can be improved by involving their husbands in at least one antenatal care visit.

Keywords: Husband, Male involvement, Antenatal care, Skilled birth attendant, Ethiopia

\footnotetext{
* Correspondence: wondeti@yahoo.com

${ }^{1}$ School of Public and Environmental Health, College of Medicine and Health

Sciences, Hawassa University, Hawassa, Ethiopia

2Department of Reproductive Health and Health Service Management,

School of Public Health, College of Health Sciences, Addis Ababa University,

Addis Ababa, Ethiopia

Full list of author information is available at the end of the article
}

(c) The Author(s). 2018 Open Access This article is distributed under the terms of the Creative Commons Attribution 4.0 International License (http://creativecommons.org/licenses/by/4.0/), which permits unrestricted use, distribution, and reproduction in any medium, provided you give appropriate credit to the original author(s) and the source, provide a link to the Creative Commons license, and indicate if changes were made. The Creative Commons Public Domain Dedication waiver (http://creativecommons.org/publicdomain/zero/1.0/) applies to the data made available in this article, unless otherwise stated. 


\section{Background}

Globally, in 2015, approximately eight hundred and thirty women were dying every day due to pregnancy and childbirth complications. Almost all these deaths (99\%) occurred in low-resource settings, and more than half occur in sub-Saharan Africa [1-3]. The probability that a 15 year-old girl in sub-Saharan Africa eventually dying from a maternal cause was as high as 1 in 36 compared to 1 in 4900 in developed Region [1, 4].

Ethiopia is one of the six countries that account for $50 \%$ of maternal deaths globally [3]. Trends in maternal mortality ratios (MMRs) in Ethiopia, however, showed a significant reduction of maternal deaths from 897 per 100,000 live births in 2000 to 353 per 100,000 live births in 2015 [1]. There is no doubt that the country will need to make huge reductions in MMRs to meet the target of MDG5 and Sustainable Development Goals (SDG3), a transformative new agenda for maternal health towards ending preventable maternal mortality [1]. This will require a great commitment from the government and its partners [5] with community effort.

The challenges of maternal mortality and morbidity in Ethiopia are aggravated by the underutilization of skilled delivery services [6]. The proportion of births with skilled attendants is still very low in Ethiopia [5, 7]. Unskilled persons assist the majority of births at home and only $16 \%$ of births are at health facilities in 2014, in Ethiopia [7]. Even though the percentage of facility births continues to be low in Ethiopia, it increased from $5 \%$ in 2000 to $16 \%$ in 2014 in the last 15 years. In Southern region, $11.7 \%$ of the women delivered by SBAs, which is lower than other similar regions in Ethiopia [7].

Ethiopian Federal Ministry of Health (EFMOH), as part of reproductive health $(\mathrm{RH})$ strategies to reduce MMR, had planned to raise the number of deliveries attended by SBAs from $16 \%$ in 2006 to $60 \%$ by 2015 [5]. This RH strategy did not consider the roles of men in maternal health services. However, the majority of studies in Ethiopia indicates men's roles as head of the households and key decision-makers of all issues including women's need for health care services. Moreover, common reasons cited by many studies in Ethiopia for the low utilization of SBAs are focused on the socio-demographic and maternal characteristics, and little has been done to involve male partners in maternal health care services $[6,8,9]$.

Evidence from an interventional study in African countries suggest that the three exposure indexes consistently and significantly associated with women's use of SBAs are husband's involvement in decision-making, couple's discussion and planning within the household, and having received counselling on birth preparedness during ANC [8]. Despite that fact, research about the association between husbands' involvement in ANC visits and women's utilization of SBAs is limited. Therefore, identifying such association would be important for policy and program planning for maternal health care, specifically to improve women's utilization of skilled birth attendants. Using a cohort study design, our study sought to determine whether husbands' involvement in ANC visits is associated with women's utilization of SBAs.

\section{Methods}

\section{Design, aim, and setting of the study}

This study employed a prospective cohort design to examine the relationship between husbands' involvement in ANC visits and women's utilization of SBAs during birth, in Sidama zone, Southern Nations, Nationalities, and People's Region (SNNPR) of Ethiopia, from June 1, 2015 to November 30, 2015. SNNPR is one of the regions in Ethiopia, with 14 administrative zones and 13 special weredas. One of the most populous zones in the region is Sidama zone. The capital of Sidama zone as well as the region is Hawassa town, which is situated $275 \mathrm{~km}$ south of Addis Ababa. The total population size of the zone was 2,966,652; of which $49.5 \%$ was females and 5.5\% are urban inhabitants $[10,11]$. The population density in the zone was $452 / \mathrm{km}^{2}$ with an average household size of 4.9 persons. Women of reproductive age (15-49 years) and children under-one-year of age were estimated to be 23 and $3 \%$ of the total population, respectively [10]. According to the zonal health department's report, there are seven primary (district) hospitals, one general hospital (a comprehensive and specialized university hospital), one-hundred and twenty-seven health centres, and five-hundred and twenty-four health posts in the zone. According to 2011 EDHS report, the total fertility rate of the region (SNNPR) was 4.9 children per woman, which was almost similar to the national fertility level of 4.8 children per woman in three years preceding the survey [12]. Skilled ANC, delivery care, and postnatal care (PNC) services (within two days after birth) utilization coverage of the region in the five years preceding the survey were $39,11.7$, and $11.1 \%$, respectively [7].

\section{Study population and sampling technique}

The study was conducted on a random sample of 709 antenatal women who were eligible to be included in this study. The sample-size was estimated by using 'Power and Sample-Size' software Program' (PS version 3.1.2) [13]. The computation was made with 95\% confidence level, $5 \%$ alpha $(\alpha)$, $80 \%$ power $(\beta)$, and with $1: 1$ ratio of independent exposed and unexposed groups. We used 90 and $82 \%$ of the women attended by SBAs (outcome variable) among women who attended ANC education with their husbands (intervention group) and those who did not attend the services (control group) respectively, from a study in Nepal [14]. The calculated sample-size indicated an appropriate sample size of 638 women. Assumed loss 
to follow-up was $10 \%$. Hence, total sample of 702 pregnant women were needed to test the hypothesis that women whose husbands were involved during ANC visit are more likely to utilize SBAs during birth compared to women whose husbands were not involved during ANC visit. Then, we applied a random sampling technique to select the study sample. First, we randomly selected eight out of twenty-one weredas in Sidama Zone using a lottery method. Lists of all pregnant women between 24th and 36th weeks of gestational age from June 01 to November 30, 2015 (i.e. 712 women) were prepared using household survey, health institutional records reviews, and by linking them at follow-up schemes with collaborations of the health extension workers (HEWs). Women on the lists were sent invitation letters to participate in the study. Finally, 709 pregnant women were included.

\section{Inclusion and exclusion criteria}

Women with a gestational age (G.A.) between 24th weeks to 36th weeks, living with their husbands for at least a year in the study area and those who initiated ANC service in the selected health institutions before or during the study period were asked to participate. Mothers were excluded if they had complications of pregnancy (high-risk pregnancy confirmed during ANC check-up), being unmarried, and those who were sick and unable to undergo an interview during the study period.

\section{Definition of exposure and outcome variables}

In this study, husbands' involvement in antenatal care (ANC) is the exposure variable- defined as- women who were accompanied by their husbands at least once for ANC visits, and women who attended ANC visits without their husbands were considered as 'non-exposed'. Women's use of skilled birth attendants (SBAs) was an outcome indicator to evaluate the effect of husbands' involvement in ANC visits. Women used SBAs - means women were assisted by SBAs during births in health institutions or at home. Skilled Birth Attendants (SBAs) are doctors, nurses, and midwives who have a special training on childbirth practices [8].

\section{Data collection}

Data were collected using a semi-structured follow-up questionnaire, which was prepared for a progressive evaluation of maternal conditions (Additional file 1). Twenty-eight nurses who were working in maternity units and five supervisors collected data after they were trained for three days. Both data collectors and supervisors had a bachelor degree in nursing and a master degree in public health, and had at least one experience in quantitative data collection. The interviews were conducted using the local language (Sidamigna and Amharic) after the questionnaire was pretested for cultural appropriateness and clarity. Data collectors were fluent speakers of both the local and Amharic languages. The questionnaire included three major components: background information of study subjects, past and current obstetric conditions, utilization status of ANC services, husband's involvement status during ANC visits, and women's utilization status of SBAs during births.

Data collections were conducted at three time points. At the beginning, data collectors approached each potential subject to inquire about their eligibility and interest in volunteering for this study. This inquiry included a description of the study, its importance for maternal health care, responsibilities for participating, and potential benefits of participating.

\section{The questions to confirm eligibility included}

Information on maternal characteristics such as month of pregnancy, pregnancy intention, initiation of ANC visit, marital status, number of U5 children currently alive, 'Are you living with your husband or not?, and 'Did your husband accompany you for at least one ANC visit in this recent pregnancy?, and information on women's background characteristics. All mothers who met the study criteria were asked to participate and give informed consent. Study aids included a client information booklet, writing pad with pen and pencil to calculate expected date of delivery (E.D.D), 'fundal height' measurement guide for abdominal palpation were given to data collectors; and telephone numbers of the study team to all HEWs for advice in case of complications or questions regarding follow up visits. During initial assessment, data collectors and supervisors estimated each woman's date of last ANC check-up (or at 9 months of pregnancy) for next contact.

The first interviews with the women were conducted at their last ANC check-up according to the estimated schedule for each woman (or at 9 months of pregnancy). It was to ascertain information on women's utilization status of ANC services (the number of ANC visits) and the status of their husbands' involvement in ANC visits (did your husband accompany you for at least one ANC visit? [yes/no]). These included a baseline evaluation and planned visits according to the schedule given for every woman. The second interviews were conducted on date of delivery (or within a week after birth) to collect data on women's place of birth and utilization status of SBAs during birth. If place of births were at health facility, data collectors checked the information available in the delivery care 'logbook'. Each specific date of interview for every woman was estimated beforehand, based on gestational age by data collectors and supervisors as well as principal investigator. In addition, HEWs at each kebele were assigned to assist data collectors during home visits according to the given schedule. The HEWs in the selected weredas used telephone reminders for 
upcoming study visits, which was no less frequently than once every month or when there was unscheduled or unexpected childbirth.

\section{Data processing and analysis}

After appropriate coding, data were entered from the completed questionnaires to computer software (SPSS version20) for analysis. Data entry was validated (logic checks including range checks and missing value checks) by visual inspection. Monitoring of the interviews occurred regularly through site visits by supervisors and principal investigator. This included ensuring all questionnaires were completed, few questionnaires were matched randomly with the source of information, and all scheduled and unscheduled visits were documented. Inconsistencies were resolved by contacting the study participants.

We hypothesized that SBA would be higher in the exposed group than in the control group. Study participants were coded as lost to follow-up if the questionnaire on delivery care was not completed. Descriptive statistics were presented mainly as frequency listings and percentages because most of the variables were categorical. For continuous variables, we computed means and standard deviations. We used a chi-square $(\mathrm{x} 2)$ goodness-of-fit test with $p$-values $<0.05$ for level of significance to test the comparability (homogeneity) of women's baseline variables (their proportions) in our sample population.

Bivariate logistic regression analyses were computed to examine the association between exposure and outcome variables. Then, we computed multivariate logistic regression analyses to evaluate the independent effects of each predictor variable on the outcome variable by controlling for confounding factors. Odds ratios with $95 \%$ confidence intervals (C.I.) were used to evaluate the direction and strength of associations. We checked presence of interaction effects between independent variables, performed an overall model evaluation, statistical test of individual predictors, and goodness-of-fit statistics of the model using SPSS software version20 (Additional file 2). As women's demographic and maternal characteristics were a priori expected to have moderation or interaction effects on the relationship between husbands' involvement and women's use of SBAs, stratified odds ratios of the exposure and outcome variables were estimated for each independent factor, but are only reported when found to be statistically significant.

\section{Results}

Of 709 study participants, $54 \%\left(n_{1}=385\right)$ reported at least one ANC visit, in which they were accompanied by their husband whereas $46 \%\left(n_{2}=324\right)$ reported that they were never accompanied by their husbands. On the first interview dates, women were asked about the total number of ANC visits and whether their husbands' were involved in at least one or not. This helped to crosscheck their first and second responses, and we took the similar (agreed) responses as a true response to ascertain exposure status. Moreover, $41 \%(n=143)$ of the women from the exposed group were observed with their husbands at health facilities for at least one ANC visit during the initial assessment. Fortunately, we did not find variations between the two responses with respect to their husbands' involvement. During the second interview sessions, 664 women (100\% of the exposed and $86 \%$ of the non-exposed groups) completed their follow-up, yielding a $93.6 \%$ response rate. Incomplete follow-up for $45(6.3 \%)$ women from the non-exposed group was due to those who changed their residence with unknown reason even though repeat visits took place.

\section{Characteristics of study subjects}

One hundred and seventy-five (26.4\%) respondents were 15 to 24 years of age and $110(16.6 \%)$ were 35 to 49 years of age when their last children were born. (Table 1) Mean age was 28.2 (SD \pm 5.43 years). Among these women, 141 (21.2\%) had no formal education, $248(37.3 \%)$ had attended primary education, and 176 $(26.5 \%)$ of the women had attained secondary education. A higher proportion $(77.3 \%, n=513)$ of the women were 'housewives'; and the majority $(67.6 \%, n=449)$ were Protestants while others belonged to Muslim, Orthodox and Catholic religion. (Table 1) The proportion of births at health facility $(329 ; 49.5 \%)$ and at home $(335 ; 50.5 \%)$ was nearly equal. Similarly, the women's responses on use of skilled birth attendants (SBAs) and health facility delivery (HFDs) were equal. The two groups of women had nearly even distributions by place of residence, age, level of education, and number of under five children at recent pregnancy (Table 1).

A higher proportion of the exposed group used SBAs compared to the non-exposed group $(67.5 \%, n=260$ versus $24.7 \%, n=69)$ ). (Table 2) Variance inflation factors (VIFs) for each covariate were between '1.06 to 1.278', indicating no multicollinearity; since the values are $<5.0$ (Additional file 3) [15]. However, the results of stratified analyses showed instability of ORs for 'initiation of ANC visits during the recent pregnancy', which has both confounding and modification effect on the relationship between the number of ANC visits and the outcome variable. Due to this reason, the variable initiation of ANC visit' dropped from the final model.

\section{Bivariate and multivariate logistic regression analyses}

Bivariate analysis showed that husbands' involvement during ANC visit was statistically significantly associated with women's use of SBAs during births [COR 6.33, 95\% C.I.: 4.5, 8.9]. (Table 2) Regarding women's background 
Table 1 Baseline characteristics of women in the two groups, in Sidama zone, Southern Ethiopia, 2015

\begin{tabular}{|c|c|c|c|c|}
\hline \multirow[b]{2}{*}{ Characteristics } & \multicolumn{3}{|c|}{ Was your husband involved at least in one ANC visit? } & \multirow[b]{2}{*}{$x^{2},(p$-value $)$} \\
\hline & Yes, $(\%)(n=385)$ & No, $(\%)(n=279)$ & Total $(N=664)$ & \\
\hline \multicolumn{5}{|l|}{ Residence } \\
\hline Urban & $194(60.1)$ & $129(39.9)$ & 323 & \multirow[t]{2}{*}{$1.117(=0.291)$} \\
\hline Rural & $191(56.0)$ & $150(44.0)$ & 341 & \\
\hline \multicolumn{5}{|l|}{ Age in year } \\
\hline $15-24$ & $103(58.9)$ & $72(41.1)$ & 175 & \multirow[t]{3}{*}{$0.090(=0.956)$} \\
\hline $25-34$ & $218(57.5)$ & $161(42.5)$ & 379 & \\
\hline $35-49$ & $64(58.2)$ & $46(41.8)$ & 110 & \\
\hline \multicolumn{5}{|l|}{ Education level } \\
\hline Tertiary & $62(62.6)$ & $37(37.4)$ & 99 & \multirow[t]{4}{*}{$3.010(=0.390)$} \\
\hline Secondary & $103(58.5)$ & $73(41.5)$ & 176 & \\
\hline Primary & $134(54.0)$ & $114(46.0)$ & 248 & \\
\hline None & $86(61.0)$ & $55(39.0)$ & 141 & \\
\hline \multicolumn{5}{|l|}{ Occupation type } \\
\hline Government employee & $64(69.6)$ & $28(30.4)$ & 92 & \multirow[t]{3}{*}{$6.159(=0.046)^{*}$} \\
\hline Businesswomen & $35(59.3)$ & $24(40.7)$ & 59 & \\
\hline Housewife & $286(55.8)$ & $227(44.2)$ & 513 & \\
\hline \multicolumn{5}{|l|}{ Religion } \\
\hline Protestant & $251(55.9)$ & $198(44.1)$ & 449 & \multirow[t]{4}{*}{$8.908(=0.031)^{*}$} \\
\hline Orthodox & $45(63.4)$ & $26(36.6)$ & 71 & \\
\hline Catholic & $47(73.4)$ & $17(26.6)$ & 64 & \\
\hline Muslim & $42(52.5)$ & $38(47.5)$ & 80 & \\
\hline \multicolumn{5}{|l|}{ Initiation of ANC visit } \\
\hline 1st trimester & $41(71.9)$ & $16(28.1)$ & 57 & \multirow[t]{3}{*}{$9.764(=0.008)^{* *}$} \\
\hline 2nd trimester & $231(60.0)$ & $154(40.0)$ & 385 & \\
\hline 3rd trimester & $113(50.9)$ & $109(49.1)$ & 222 & \\
\hline \multicolumn{5}{|l|}{ Number of ANC visits } \\
\hline $4+$ & $64(76.2)$ & $20(23.8)$ & 84 & \multirow[t]{2}{*}{$13.087(<0.001)^{* * *}$} \\
\hline 1 to 3 & $321(55.3)$ & $259(44.7)$ & 580 & \\
\hline \multicolumn{5}{|l|}{ Number of under 5 children } \\
\hline$<1$ & $127(62.0)$ & $78(38.0)$ & 205 & \multirow[t]{2}{*}{$1.918(=0.166)$} \\
\hline$>1$ & $258(56.2)$ & $201(43.8)$ & 459 & \\
\hline \multicolumn{5}{|l|}{ Is the pregnancy planned? } \\
\hline Yes & $280(64.2)$ & $156(35.8)$ & 436 & \multirow[t]{2}{*}{$20.282(<0.001)^{* * *}$} \\
\hline No & 105 & $123(53.9)$ & 228 & \\
\hline
\end{tabular}

***P-value $<0.001,{ }^{* *} p$-value $<0.01$, and ${ }^{*} P$-value $<0.05$, indicate the significance differences of the two groups (women with husbands' involvement and without involvement by indicated variables)

and maternal factors, nine variables were significantly associated with women's use of SBAs during births, though there was a weak association with women's age. All independent variables, which had a $p$-value $<0.25$ in the bivariate analysis were included in a multivariate regression analysis to ascertain their independent effects on women's utilization of SBAs during deliveries. (Table 2) On a multivariate analysis, husbands' involvement during
ANC visits and women's use of SBAs during birth showed a strong significant association [AOR 6.27, 95\% C.I.: 4.2, 9.3] (Table 2).

There was no homogeneity of the odds ratios for the relationship between 'husbands' involvement during ANC visit' and 'women's use of SBA' across categories of place of residence and women's age (as layer variables). (Table 3) However, across categories of women's education (as layer 
Table 2 Logistic regression analysis of skilled birth attendant utilization by selected characteristics, Sidama Zone, Ethiopia, 2015

\begin{tabular}{|c|c|c|c|c|c|}
\hline \multirow[t]{2}{*}{ Characteristics } & & \multicolumn{4}{|c|}{ Have you received SBAs' service? } \\
\hline & & Yes, $n(\%)$ & No, $n(\%)$ & COR (95\%C.I.) & AOR (95\%C.I.) \\
\hline \multirow[t]{2}{*}{ Husband involved in ANC } & Yes & $260(67.5)$ & $125(32.5)$ & $6.33(4.5,8.9)^{*}$ & $6.27(4.2,9.3)^{*}$ \\
\hline & No & $69(24.7)$ & $210(75.3)$ & 1.00 & 1.00 \\
\hline \multirow[t]{2}{*}{ Place of residence } & Urban & $193(59.8)$ & $130(40.2)$ & $2.2(1.6,3.0)^{*}$ & $1.7(1.14,2.5)^{*}$ \\
\hline & Rural & $136(39.9)$ & $205(60.1)$ & 1.00 & 1.00 \\
\hline \multirow[t]{3}{*}{ Age in year } & $15-24$ & $100(57.1)$ & $75(42.9)$ & $1.9(1.2,3.1)^{*}$ & - \\
\hline & $25-34$ & $184(48.5)$ & $195(51.5)$ & $1.4(0.9,2.1)$ & - \\
\hline & $35-49$ & $45(40.9)$ & $65(59.1)$ & 1.00 & - \\
\hline \multirow[t]{4}{*}{ Education level } & Tertiary & $61(61.6)$ & $38(38.4)$ & $1.9(1.14,3.3)^{*}$ & $1.6(0.8,2.9)$ \\
\hline & Secondary & $102(58.0)$ & $74(42.0)$ & $1.7(1.06,2.6)^{*}$ & $1.3(0.7,2.2)$ \\
\hline & Primary & $102(41.1)$ & $146(58.9)$ & $0.8(0.5,1.3)$ & $0.6(0.4,1.1)$ \\
\hline & None & $64(45.4)$ & 77 (54.6) & 1.00 & 1.00 \\
\hline \multirow[t]{3}{*}{ Occupation type } & Government employee & $56(60.9)$ & $36(39.1)$ & $1.8(1.2,2.8)^{*}$ & - \\
\hline & Businesswomen & $36(61.0)$ & $23(39.0)$ & $1.8(1.05,3.2)^{*}$ & - \\
\hline & Housewife & $237(46.2)$ & $276(53.8)$ & 1.00 & - \\
\hline \multirow[t]{4}{*}{ Religions } & Protestant & $207(46.1)$ & $242(53.9)$ & $1.5(0.9-2.5)$ & $1.7(0.9,3.1)$ \\
\hline & Orthodox & $49(69.0)$ & $22(31.0)$ & $3.9(1.9-7.8)^{*}$ & $3.8(1.7,8.6)^{*}$ \\
\hline & Catholic & $44(68.8)$ & $20(31.2)$ & $3.8(1.9-7.8)^{*}$ & $3.4(1.5,7.8)^{*}$ \\
\hline & Muslim & $29(36.2)$ & $51(63.8)$ & 1.00 & 1.00 \\
\hline \multirow[t]{2}{*}{ Planned pregnancy } & Yes & $262(60.1)$ & $174(39.9)$ & $3.6(2.6-5.1)^{*}$ & $2.5(1.7,3.7)^{*}$ \\
\hline & No & $67(29.4)$ & $161(70.6)$ & 1.00 & 1.00 \\
\hline \multirow[t]{2}{*}{ Number of U5 year children } & $\leq 1$ & $135(65.9)$ & $70(34.1)$ & $2.6(1.9-3.7)^{*}$ & $2.5(1.6,3.8)^{*}$ \\
\hline & $>1$ & $194(42.3)$ & $265(57.7)$ & 1.00 & 1.00 \\
\hline \multirow[t]{3}{*}{ Initiation of ANC visit } & 1st trimester & $37(64.9)$ & $20(35.1)$ & $3.2(1.7,5.8)^{*}$ & - \\
\hline & 2nd trimester & $210(54.5)$ & $175(45.5)$ & $2.0(1.5,2.9)^{*}$ & - \\
\hline & 3rd trimester & $82(36.9)$ & $140(63.1)$ & 1.00 & - \\
\hline \multirow[t]{2}{*}{ Number of ANC visits } & $4+$ & 66 (78.6) & $18(21.4)$ & $4.4(2.6-7.6)^{*}$ & $3.3(1.7,6.5)^{*}$ \\
\hline & 1 to 3 & $263(45.3)$ & 317 (54.7) & 1.00 & 1.00 \\
\hline
\end{tabular}

COR Crude Odds Ratio, AOR Adjusted Odds Ratio

*Where $95 \%$ C.I. does not include 'one', it shows a significant association between the outcome and the factor

The sign"-----"indicates the variable was not included in the multivariate analysis

variable), a significance value of homogeneity test was greater than 0.10, indicating homogeneous odds ratios among categories. (Table 3).

Among women's background and maternal factors, place of residence, religion, number of under five children, and number of ANC visits attended by women during the recent pregnancy were found to be significant predictors for women's use of SBAs during births, after controlling for confounding variables. Women with one or no U5 children during the recent pregnancy were 2.5 times more

Table 3 Homogeneity tests for Odds Ratio of factors (layer variable), in Sidama zone, Southern Ethiopia, 2015

\begin{tabular}{lllll}
\hline Layer variable (by categories) & & Chi-Squared & df & Asymp. Sig. (2-sided) \\
\hline Place of residence (2 categories.) & Breslow-Day & 9.808 & 1 & 0.002 \\
& Tarone's & 9.806 & 1 & 0.002 \\
Women's age (3 categories) & Breslow-Day & 21.613 & 2 & 0.000 \\
& Tarone's & 21.455 & 2 & 0.000 \\
Women's education level (4 categories) & Breslow-Day & 4.114 & 3 & $0.249^{*}$ \\
& Tarone's & 4.112 & 3 & $0.250^{*}$ \\
\hline
\end{tabular}

${ }^{*} p$-value $>0.10$, indicating homogeneity of the odds ratios among categories of a particular variable 
likely to use SBAs during births compared to women with more than one U5 children during the recent births [AOR 2.5, 95\%C.I.: 1.6, 3.8]. Similarly, urban women were 1.7 times more likely to use SBAs during births compared to rural women [AOR 1.7, 95\% C.I.: 1.14, 2.5]. (Table 2) Women who belong to Orthodox [AOR 3.8, 95\% C.I.: 1.7, 8.6] and Catholic [AOR 3.4, 95\% C.I.: 1.5, 7.8] religions were 3.8 and 3.4 times more likely to use SBAs during births compared to Muslim women. (Table 2).

The odds of using SBAs during birth for women with planned pregnancies were 2.5 more times as likely as women with unplanned pregnancies [AOR 2.5, 95\%C.I.: 1.7, 3.7]. Women who attended four or more ANC visits during recent pregnancies were 3.3 times more likely to use SBAs during birth compared to women who attended less than or equal to three ANC visits [AOR 3.3, 95\% C.I.: 1.7, 6.5]. In addition, there was a positive relationship between number of ANC visits and odds of using SBAs during births. (Table 2).

\section{Discussion}

A higher proportion of women from the exposed group attended skilled assistance during birth compared to the non-exposed group. Husbands' involvement in their wives' ANC visits was an important predictor found to be strongly and significantly associated with women's use of SBAs during birth. This is consistent with other studies in Africa including Ethiopia, and Asia [16-20]. This could be due to a man involved in ANC who is more likely to discuss and jointly decide on his wife's place of birth than an uninvolved man. This is supported by studies in Ethiopia and Uganda [16, 21]. Male partners' concern and the presence of open discussion between partners may help a woman to use SBAs during birth. Similarly, our finding reinforces studies in Uganda [18] and Bangladesh [19] showing that women were more likely to have better outcomes when their husbands were directly involved in maternal health care by attending ANC visits and by supporting them during pregnancy. This implies that the influences from other people (especially, partners) are important determinants of women's delivery place $[8,17,20]$.

There were variations in the influence of husbands' involvement during ANC visits on women's use of SBAs across categories of residence and women's age, although it did not differ with respect of categories of women's education levels. This implies that women's odds of using SBAs during births may be increased by targeting husbands of both rural women and young women (age 15-25 years old) to be involved in their wives' ANC visits. Women who reside in urban places were more likely to use SBAs during births compared to rural women. This is consistent with other studies in Ethiopia and other African countries [6, 9, 22]. A likely explanation for this relationship is that urban women are more accessible for health information through either mass media or other sources. Moreover, as in most sub-Saharan African countries, urban women in Ethiopia tend to benefit from relatively easy access to maternal health services [22]. However, currently, the Ethiopian government has tried to reach rural communities with health information through HEWs as well as some electronic media like television and mobile phones.

Women who belong to Orthodox and Catholic religions were more likely to use SBAs during birth than women belong to Muslim religion. This is consistent with other studies in Ethiopia, Asia, and Kenya [6, 22-29]. A previous study in Ethiopia, however, did not find a significant association between religion and SBAs utilization [9]. This difference might be due to the difference in study context, study design and sample size. Further studies are needed to ascertain the discrepancies with respect to religion.

The relationship between level of education and women's use of SBAs during birth did not attain statistical significance. It is similar with another study in Ethiopia that showed women's education is a weak predictor of the use of skilled assistance at birth [6]. Other studies in Ethiopia [9, 11, 22, 28], however, documented that women's education is a major factor influencing maternal health care utilization, but these addressed maternity care services in general and utilization of SBAs not as a separate issue. It is commonly believed that education serves as proxy for information and knowledge of available health care services [30]. Moreover, education enhances level of women's autonomy and increases decision-making power that results in improved freedom to make decisions including the use of maternal health care [31]. A study in Tanzania reported that educated women were more likely to make decisions to use assistance from medical personnel at birth themselves compared to their uneducated counterparts [32]. Similarly, studies in Bangladesh [33] and Turkey [34] found that women's education was a strong determinant of the use of skilled assistance at birth. Possible explanations for the differences may be, first, due to differences in study designs and sample sizes; second, it could be due to an effect modification between women's education levels and our main exposure variable in the association with the outcome variable. So, how women's education levels influence SBAs utilization with and without the influence of husbands require further study.

The association of women's use of SBAs during birth with the number of ANC visits, the number of under five children, and the pregnancy intention are consistent with three studies in Ethiopia [6,35,36], studies in Kenya [17, 37], Tanzania [38] and Nepal [39]. It is, however, not only the quantity but also the quality of ANC that influences care seeking during birth [8]. Although 
this study did not address quality of ANC services, a study in Africa showed that women with the highest focused ANC Index scores (care involved both quantity and quality) were three times more likely to deliver in health facilities than women with the lowest scores. This illustrates that even in an area where women have a strong preference to use traditional birth attendants for delivery, quality and quantity of ANC can have a major impact on care-seeking [8]. Women who had one or no under-five children were more likely to use SBAs during birth than those with more than one. Similarly, women whose pregnancy was planned were more likely to use SBAs during birth compared to women with unplanned pregnancy. This is consistent with studies in South and South-East Ethiopia [6, 35] and Kenya [17, 37]. Women with two or more under five children may prefer to deliver at home because of experiences from previous birth. Parents with fewer children lack experience and thus may seek more easily professional care $[9,28]$. In addition, the first deliveries tend to be more difficult and that may motivate women for institutional delivery $[6,28]$.

\section{Study limitation}

Loss of follow up was a limitation in this cohort study. Respondents often changed their place of residence during follow-up time. To manage this, we tried repeated visits during data collection periods. To examine the effect of the lost follow-up cases, we computed an intent-to-treat analysis and there was no significant difference on the outcomes. The other potential biases in this study may be social desirability bias in favour of their husbands' involvement in ANC service. To reduce this, we tried to interview each woman in a separate room by explaining the benefits of their honest responses for improvement of maternal health services, and we used repeated interviews (before and after delivery) to ensure the response was genuine. Further limitation of this study is data on service quality were not included. Also data on household income were incomplete, since most respondents did not volunteer to respond to such questions due to unknown reasons. This may have influenced both husbands' involvement and women's use of skilled services.

\section{Strengths of the study}

The strengths of this study were, first, a cohort design and an adequate sample size. Secondly, the observations of up to $41 \%$ of women being accompanied by their husbands lend credence to the findings from the interviews. Moreover, it is the first study in the region to determine the relationship between husbands' involvement in ANC services and women's utilization of skilled birth attendants during delivery.

\section{Conclusions and recommendations}

The strong relationship between husband's involvement during ANC visits and women's use of SBAs during birth implies that raising awareness about husbands' involvement during ANC visits through mass media, religious leaders and community elders should be given due attention, especially in regions and areas with contextual similarities. Besides that, there is a need to promote husbands' involvement in their wives' ANC visits by targeting large proportions of rural and young women. Further, it is necessary to provide information and advice on the frequency of ANC visits, at least four visits per pregnancy through contextual based couple's ANC counselling sessions. Therefore, there is a need for planners of maternal health programs to develop contextual-based approaches that promote husbands' involvement in maternal health care at Wereda, Zone and Regional levels. Our findings also strongly recommend a policy to mainstream male involvement in routine maternal health care. Such policies should address husbands' roles and constraints, as well as an educational component to sensitize husbands to the benefits of their involvement in pregnancy care and outcomes. Based on our findings, we also strongly recommend health institutions to start well-organized ANC couples' counselling sessions at least once after the first ANC visit of every pregnant woman based on the women's consent. Antenatal care couple-counselling sessions should address the benefits of skilled maternal health care in general; and the benefits of repeated ANC visits and postpartum services in particular. For men, such efforts could help to deflate the assumption that maternal health care is an exclusively women's concern.

\section{Additional files}

\section{Additional file 1: Participants' Information Sheet \& Consent-form.} (PDF 219 kb)

Additional file 2: SPSS Output-logistic regression table. The data described the output of a multivariate analysis of selected predictors for women's utilization of skilled birth attendants; and it is the best-fitted model selected from six models constructed by forward log-likelihood methods in SPSS. (PDF $176 \mathrm{~kb}$ )

Additional file 3: Multicollinearity statistics output table. The data described the multicollinearity statistics output-i.e. the tolerance and Variance Inflation Factor- of selected independent variables. (PDF $168 \mathrm{~kb}$ )

Additional file 4: English version Interview Questionnaire. (PDF 271 kb)

\section{Abbreviations}

ANC: Antenatal Care; AOR: Adjusted Odds Ratio; Cl: Confidence Interval; COR: Crude Odds Ratio; E.D.D.: Expected Date of Delivery;i EDHS: Ethiopia Demographic and Health Survey; EFMOH: Ethiopia Federal Ministry Of Health; G.A.: Gestational Age; HEW: Health Extension Worker; MMR: Maternal Mortality Rate/Ratio; OR: Odds Ratio; PNC: Postnatal Care; RH: Reproductive Health; SBA: Skilled Birth Attendant; SDG: Sustainable Development Goals; SNNPR: Southern Nation Nationality and People's Region; SPSS: Statistical Software Package for Social Science; VIF: Variance Inflation Factor 


\section{Acknowledgements}

We are grateful to Addis Ababa University School of Public Health for supporting this study. We would like to extend our appreciation to the entire Wereda Health Team of Regional and Sidama Zone Health Bureaus and Wereda Health Offices for their co-operation. Finally, our special thanks go to data collectors and study participants who took part in this study.

\section{Authors' contributions}

WT and WD contributed equally during the process of proposal development. WT participated in data collection, data analysis and in preparing the draft manuscript. WT and WD made significant contributions in revising the manuscript. Finally, both authors read and approved the final version of the manuscript.

\section{Ethics approval and consent to participate}

Before the commencement of the study, ethical approval letter was obtained from the Institutional Review Board of the College of Health Sciences, Addis Ababa University in Ethiopia (Protocol No. 067/13/SPH and Approval Meeting No.054/13). Then we obtained permission letters from South Region and Sidama Zone Health Bureaus, as well as from Weredas Health Offices and health institutions (Additional file 4). Before started data collection, written informed consent was obtained from respondents. With regard to participants under the age of 18 years, the parent provided written informed consent on behalf of them. They were informed to interrupt the interview at any time that they desire if they are not willing to continue with the interview. To ensure confidentiality, codes instead of names were used during data entry and in depicting the results of the study. In addition, the questionnaires and other collected information were kept locked and only the P.I had access. Participants found sick were referred to the nearby health centre for medical care.

\section{Consent for publication}

Not applicable.

\section{Competing interests}

The authors declare that they have no competing interests.

\section{Publisher's Note}

Springer Nature remains neutral with regard to jurisdictional claims in published maps and institutional affiliations.

\section{Author details \\ ${ }^{1}$ School of Public and Environmental Health, College of Medicine and Health Sciences, Hawassa University, Hawassa, Ethiopia. ${ }^{2}$ Department of Reproductive Health and Health Service Management, School of Public Health, College of Health Sciences, Addis Ababa University, Addis Ababa, Ethiopia. ${ }^{3}$ Department of Preventive Medicine, School of Public Health, College of Health Sciences, Addis Ababa University, Addis Ababa, Ethiopia.}

Received: 26 June 2017 Accepted: 27 July 2018

\section{Published online: 03 August 2018}

\section{References}

1. World Health Organization (WHO). Trends in maternal mortality: 1990 to 2015. Estimates by WHO, UNICEF, UNFPA, the World Bank and the United Nations population division. Geneva: WHO. p. 2015. http://apps.who.int/iris/ bitstream/10665/194254/1/9789241565141_eng.pdf?ua=1. Accessed 1 Aug 2018.

2. World Health Organization (WHO). Trends in Maternal Mortality: 1990 to 2010. Geneva Switzerland: WHO; 2014. http://apps.who.int/iris/bitstream/ handle/10665/44874/9789241503631_eng.pdf?sequence=1. Accessed 1 Aug 2018.

3. Hogan MC, Foreman KJ, Naghavi M, Ahn SY, Wang M, Makela SM, et al. Maternal mortality for 181 countries, 1980-2008: a systematic analysis of progress towards millennium development goal 5. Lancet. 2010;375(9726): 1609-23.

4. World Health Organization. Global Health Observatory (GHO) Data, 2015. http://apps.who.int/iris/bitstream/handle/10665/170250/9789240694439 eng.pdf? sequence=1. Accessed 1 Aug 2018.

5. UNDP- Ethiopia. Analyzing Performance and Regional Disparities in Health Outcomes in Ethiopia; 2012; No.2/2012. http://www.undp.org/content/dam/
ethiopia/docs/Analyzing\%20Regional\%20Performance\%20and\%20Disparities \%20in\%20Health\%20outcome\%20in\%20Ethiopia.pdf. Accessed 1 Aug 2018.

6. Fekadu M, Regassa N. Skilled delivery care service utilization in Ethiopia: analysis of rural-urban differentials based on national demographic and health survey (DHS) data. Afr Health Sci. 2014;14(4) https://doi.org/10.4314/ahs.v14i4.29.

7. Ethiopia Mini Demographic and Health Survey 2014. Central statistical agency; Addis Ababa, Ethiopia 2016.

8. Family Care International (FCl'S Skilled Care Initiatives). Testing Approaches for Increasing Skilled Care during Childbirth: Key Findings. Technical Brief, October 2007. http://www.familycareintl.org/UserFiles/File/

SCl\%20Kenya\%20Report\%20March\%202008.pdf. Accessed 1 Aug 2018.

9. Mekonnen Y., Mekonnen A. Utilization of maternal health Care Services in Ethiopia Calverton, Maryland, USA: ORC macro: 2002.

10. FDRE. Central statistics authority (CSA): summary and statistical report of the 2007 population and housing census results of Ethiopia. Addis Ababa: UNFPA, Population Census Commission; 2008

11. Regassa N. Antenatal and postnatal care service utilization in southern Ethiopia: a population-based study. Afr Health Sci. 2011;11(3):390-7.

12. Central Statistical Agency (CSA) [Ethiopia] and ICF Macro. Ethiopia Demographic and Health Survey 2011. Addis Ababa, Ethiopia, and Calverton, Maryland, USA: Central Statistical Agency and ICF Macro. 2012.

13. Dupont WD, Plummer WD. Power and sample size calculations for studies involving linear regression. Control Clin Trials. 1998;19:589-601. http://biostat. mc.vanderbilt.edu/wiki/Main/PowerSampleSize. Accessed 1 Aug 2018.

14. Mullany BC, Becker S, Hindin MJ. The impact of including husbands in antenatal health education services on maternal health practices in urban Nepal: results from a randomized controlled trial. Health Educ Res. 2007;22(2):166-76.

15. Robert M. O'brien. A Caution Regarding Rules of Thumb for Variance Inflation Factors. Quality and Quantity. 2007:41:673-690. USA; Springer, 2007.

16. Lingerh W, Ababeye B, Ali I, Nigatu T, et al. Magnitude and factors that affect males' involvement in deciding partners' place of delivery in Tiyo District of Oromia region. Ethiopia Ethiop J Health Dev. 2014:6-13.

17. Judith NM, Ann M, Samwel M, Vincent M. Male involvement in maternal health care as a determinant of utilization of skilled birth attendants in Kenya. ICF Maryland, USA: United States Agency for International Development.DHS working papers; 2013. No. 93

18. Kabakyenga JK, Östergren PO, Turyakira E, Pettersson KO. Influence of birth preparedness, decision-making on location of birth and assistance by skilled birth attendants among women in south-western Uganda. PLoS One. 2012; 7(4):e35747.

19. Story TW, Burgard SS, Lori RJ, Taleb F, Ali AN, Hoque ED. Husbands' involvement in delivery care utilization in rural Bangladesh: a qualitative study. BMC Pregnancy Childbirth. 2012;12:28.

20. Rahman MM, Haque SE, Zahan MS. Factors affecting the utilization of postpartum care among young mothers in Bangladesh. Health Soc Care Community. 2011;19(2):138-47.

21. Kabakyenga JK, Ostergren PO, Turyakira E, Pettersson KO. Influence of birth preparedness, decision-making on location of birth and assistance by skilled birth attendants among women in southwestern Uganda. PLoS one. 2012; 7(4):e35747. https://doi.org/10.1371/journal.pone.0035747.

22. Abera M, Belachew T. Predictors of safe delivery service utilization in Arsi zone, south-East Ethiopia. Ethiop J Health Sci. 2012;21(3):101-13.

23. Baral YR, Lyons K, Skinner J, van Teijlingen ER. Determinants of skilled birth attendants for delivery in Nepal. Kathmandu University Med J. 2010:8(3):325-32.

24. Singh A, Kumar A, Pranjali P. Utilization of maternal healthcare among adolescent mothers in urban India: evidence from DLHS-3. PeerJ. 2014;2: e592. https://doi.org/10.7717/peerj.592.

25. Shah N, Rohra DK, Shams H, Khan NH. Home Deliveries: Reasons and Adverse Outcomes in Women Presenting to a Tertiary Care Hospital. J Pak Med Assoc. 2010;60(7):555.

26. Wabuge E.M. Obstetric Care in the Home Delivery among women in Lugari District, Western Province, Kenya. JKUAT Abstracts of Post Graduate Thesis. 2010. Available at http://www.researchkenya.or.ke/api/content/abstract/ Lugari+District. Accessed 1 Aug 2018

27. Wanjira C, M. Mwangi, E. Mathenge, G. Mbugua. Delivery Practices and Associated Factors among Mothers Seeking Child Welfare Services in Selected Health Facilities in Nyandarua South District, Kenya. BMC Public Health. 2011; $11(1): 360$.

28. Pavilainen Miia and Matti Salo. Men's socio-demographic background and maternal health care utilization in Ethiopia. International health. August 2013. 
29. Mehari, A. Levels and determinants of use of institutional delivery care services among women of childbearing age in Ethiopia: analysis of EDHS 2000 and 2005 data. ICF International Calverton, Maryland, USA, 2013.

30. Babalola S, Fatusi A. Determinants of use of maternal health services in Nigeria-- looking beyond individual and household factors. BMC Pregnancy Childbirth. 2009;9:43. https://doi.org/10.1186/1471-2393-9-43.

31. Acharya DR, Bell JS, Simkhada P, Van Teijlingen ER, Regmi PR. Women's autonomy in household decision-making: a demographic study in Nepal. Reprod Health. 2010; https://doi.org/10.1186/1742-4755-7-15.

32. Mrisho, M., Schellenberg, J.A., Mushi,A.K, Obrist,B., Mshinda, H., Tanner,M., Schellenberg, D. Factors affecting home delivery in rural Tanzania, Tropical Medicine \& International Health. 2007; volume 12, Issue 7 pages 862-872.

33. Chakraborty N, Islam MA, Chowdhury Rl, Wasimul Bari W, Akhter HH. Determinants of the use of maternal health services in rural Bangladesh. Health Promot Int. 2003:18(4):327-37.

34. Celik Y, Hotchkiss DR. The socio-economic determinants of maternal health care utilization in Turkey. Soc Sci Med. 2000;50(12):1797-806.

35. Amano A, Gebeyehu A, Birhanu Z. Institutional delivery service utilization in Munisa Woreda, south East Ethiopia: a community based cross-sectional study. BMC; Pregnancy and Childbirth. 2012;12:105.

36. Teferra AS, Alemu FM, Woldeyohannes SM. Institutional delivery service utilization, and associated factors among mothers who gave birth in the last 12 months in Sekela District, North West of Ethiopia: A communitybased cross sectional study. BMC, Pregnancy Childbirth. 2012;12:74. https:// www.ncbi.nlm.nih.gov/pmc/articles/PMC3449175/pdf/1471-2393-12-74.pdf. Accessed 1 Aug 2018.

37. Van Eijk A, Bles H, Odhiambo F, Ayisi J, Blokland I, et al. Use of antenatal services and delivery care among women in rural western Kenya: a community based survey. J Reprod Health. 2006;3(2):1-9.

38. Lwelamira J, Safari J. Choice of place for childbirth: prevalence and determinants of health facility delivery among women in Bahi District, Central Tanzania. Asian J Med Sci. 2012;4(3):105-12. ISSN: 2040-8773

39. Karkee R, Binns CW, Lee AH. Determinants of facility delivery after implementation of safer mother programme in Nepal: a prospective cohort study. BMC Pregnancy and Childbirth. 2013;13:193.

Ready to submit your research? Choose BMC and benefit from:

- fast, convenient online submission

- thorough peer review by experienced researchers in your field

- rapid publication on acceptance

- support for research data, including large and complex data types

- gold Open Access which fosters wider collaboration and increased citations

- maximum visibility for your research: over $100 \mathrm{M}$ website views per year

At $\mathrm{BMC}$, research is always in progress.

Learn more biomedcentral.com/submissions 